\title{
Emergency Stenting of the Extracranial Internal Carotid Artery in Combination with Anterior Circulation Thrombectomy in Acute Ischemic Stroke: A Retrospective Multicenter Study
}

\author{
D. Behme, A. Mpotsaris, P. Zeyen, M.N. Psychogios, A. Kowoll, C.J. Maurer, F. Joachimski, J. Liman, K. Wasser, C. Kabbasch, A. Berlis,
}

M. Knauth, T. Liebig, and W. Weber

\begin{abstract}
BACKGROUND AND PURPOSE: Several small case series reported a favorable clinical outcome for emergency stent placement in the extracranial internal carotid artery combined with mechanical thrombectomy in acute stroke. The rate of postinterventional symptomatic intracranial hemorrhages was reported to be as high as $20 \%$. Therefore, we investigated the safety and efficacy of this technique in a large multicentric cohort.
\end{abstract}

MATERIALS AND METHODS: The data bases of 4 German stroke centers were screened for all patients who received emergency stent placement of the extracranial internal carotid artery in combination with mechanical thrombectomy of the anterior circulation between 2007 and 2014. The primary outcome measure was the rate of symptomatic intracranial hemorrhage according to the European Cooperative Acute Stroke Study III criteria; secondary outcome measures included the angiographic revascularization results and clinical outcome.

RESULTS: One hundred seventy patients with a median age of 64 years (range, 25-88 years) were treated. They presented after a median of 98 minutes (range, 52-160 minutes) with a median NIHSS score of 15 (range, 12-19). Symptomatic intracranial hemorrhages occurred in $15 / 170$ (9\%) patients; there was no statistically significant difference among groups pertaining to age, sex, intravenous rtPA, procedural timings, and the rate of successful recanalization. In 130/170 (77\%) patients, a TICl score of $\geq 2 \mathrm{~b}$ could be achieved. The in-hospital mortality rate was $19 \%$, and $36 \%$ of patients had a favorable outcome at follow-up.

CONCLUSIONS: Emergency stent placement in the extracranial internal carotid artery in combination with anterior circulation thrombectomy is effective and safe. It is not associated with a significantly higher risk of symptomatic intracranial hemorrhage compared with published series for mechanical thrombectomy alone.

ABBREVIATIONS: $\mathrm{PH}=$ parenchymal hematoma; $\mathrm{sICH}=$ symptomatic intracranial hemorrhage

$\mathbf{T}$ en-to-twenty percent of patients with acute ischemic stroke have a high-grade ipsilateral extracranial ICA stenosis, which usually causes major stroke if an additional intracranial large-

Received February 26, 2015; accepted after revision May 13.

From the Departments of Neuroradiology (D.B., M.N.P., M.K.) and Neurology (J.L., K.W.), Georg-August-University Göttingen, University Medical Center, Göttingen, Germany; Department of Radiology and Neuroradiology (A.M., P.Z., C.K., T.L.), University Cologne, University Hospital Cologne, Cologne, Germany; Department of Radiology and Neuroradiology (A.K., W.W.), Ruhr-University-Bochum, University Medical Center Langendreer, Bochum, Germany; and Departments of Radiology and Neuroradiology (C.J.M., A.B.), and Neurology (F.J.), Klinikum Augsburg, Augsburg, Germany.

Paper previously presented at: Annual Meeting of the Anatomy-Biology-Clinical Correlations-Working Group in Interventional Radiology, January 18-23, 2015; Val d Isere, France; and European Stroke Organization Conference, April 17-19, 2015; Glasgow, UK. This work received no private or public funding and no specific financial support.

Please address correspondence to Daniel Behme, MD, Department of Neuroradiology, University Medical Center Göttingen, Georg-August-University Göttingen, RobertKoch-Str 4037075 Göttingen; e-mail: daniel.behme@med.uni-goettingen.de

三 Indicates article with supplemental on-line table.

http://dx.doi.org/10.3174/ajnr.A4459 artery occlusion of the anterior circulation is present. ${ }^{1,2}$ In such a cohort, IV thrombolysis alone has a very limited rate of successful recanalization. ${ }^{3}$ Endovascular therapy is an option in these cases, consisting of a stent implantation at the level of the ICA stenosis/ occlusion in conjunction with mechanical thrombectomy before or after the stent placement. Several small case series reported promising results when this combined approach was performed. ${ }^{4-9}$ One of the major concerns in these patients is the risk of postinterventional symptomatic intracranial hemorrhage (sICH), which may be influenced by the mandatory antiplatelet medication of the stent-placement procedure. The reported rate of sICH varies considerably in the literature, ranging from $0 \%$ to $20 \% .^{5-10}$ Unfortunately, the small number of patients included in these series limits the validity of these findings. Some important randomized trials excluded patients with high-grade ipsilateral ICA stenosis (eg, the Solitaire Flow Restoration Device versus the Merci Retriever in Patients with Acute Ischemic Stroke and the Trevo versus Merci Retrievers 
for Thrombectomy Revascularisation of Large Vessel Occlusions in Acute Ischemic Stroke), ${ }^{11,12}$ while other recently published studies like a Randomized Trial of Intra-Arterial Treatment for Acute Ischemic Stroke or the Randomized Assessment of Rapid Endovascular Treatment of Ischemic Stroke trial included relatively small numbers of patients with tandem occlusions (30 [13\%] and 21 [13\%], respectively). ${ }^{13,14}$

The aim of this retrospective study was to determine the risk of sICH and the angiographic results and the clinical outcome after emergency ICA stent placement in combination with anterior circulation thrombectomy in a large multicentric cohort.

\section{MATERIALS AND METHODS}

We conducted a retrospective multicenter study of all patients who received combined extracranial ICA stent placement and anterior circulation thrombectomy between 2007 and 2014. According to the institutional guidelines, no ethics committee approval was required for this retrospective observational study. The clinical results of some of these cases have been published in case series before. ${ }^{4,5,7,15,16}$ All 4 centers screened their prospectively kept neurointerventional data bases for eligible patients according to the following inclusion and exclusion criteria.

\section{Inclusion Criteria}

The centers were free to include either all patients since 2007 (before the introduction of stent retrievers for mechanical thrombectomy) or only patients who received a stent retriever and/or direct aspiration treatment.

Eligibility for mechanical thrombectomy was decided at the local institution according to the guidelines of each center. $\mathrm{Pa}$ tients were eligible for concomitant IV thrombolysis according to the guidelines of the German Society of Neurologists. There were no general limitations on procedural timings, age, or baseline NIHSS score. Patients had to present with an angiographically (CTA or DSA) proved high-grade stenosis or occlusion of the ipsilateral ICA and additional large-artery occlusion of the anterior circulation. A high-grade ipsilateral stenosis was thereby defined as a stenosis of $\geq 70 \%$ according to the NASCET criteria. Anterior large-artery occlusions were subdivided into terminal ICA, carotid-T, and MCA occlusions.

Patients were included only if the ipsilateral ICA was stented and the occlusion of the anterior circulation was treated either in an antegrade (stent before thrombectomy) or retrograde (stent after thrombectomy) fashion. There was no limitation on the stent used or on the technique for the intracranial thrombectomy.

All patients were included independent of the administered antiplatelet medication, which was different in all 4 centers.

The antiplatelet regimens were as follows:

Center A: If the patient had no prior medication with dual antiplatelets before the intervention, eptifibatide was continuously infused for 24 hours (after an initial bolus [ $180 \mathrm{mcg} / \mathrm{kg}$ for 2 minutes]) to prevent secondary stent occlusion. Patients were monitored in the intensive care unit postinterventionally. A control CT scan was obtained within 24 hours. After exclusion of a relevant intracranial hemorrhage, the regimen was switched to a secondary prophylaxis of stent occlusion based on a dual antiplatelet therapy: Under continuous IV eptifibatide, patients re- ceived a loading dose of $300 \mathrm{mg}$ clopidogrel and $500 \mathrm{mg}$ aspirin. Patients with daily aspirin medication before the intervention did not receive an aspirin loading dose. The administration of eptifibatide was stopped 4 hours after loading with clopidogrel (and aspirin whenever applicable). Patients continued with life-long aspirin $(100 \mathrm{mg} /$ day $)$ and additional clopidogrel (75 mg/day) for 8 weeks.

Center B: Patients received an IV bolus of $500 \mathrm{mg}$ aspirin directly before stent placement and, additionally, $375 \mathrm{mg}$ clopidogrel over a nasogastric tube. After exclusion of a relevant intracranial hemorrhage (control CT scan within 24 hours), the dual antiplatelet medication with aspirin (100 mg/day) and clopidogrel (75 mg/day) was continued for 3 months and then switched to a life-long aspirin (100 mg/day) monotherapy.

Center C: All patients who were not on an antiplatelet medication before the treatment received a weight-adapted bolus of tirofiban followed by a continuous IV infusion for 24 hours. After exclusion of a cerebral hemorrhage (CT scan), $500 \mathrm{mg}$ aspirin and $300 \mathrm{mg}$ clopidogrel were given orally or through a nasogastric tube. Aspirin (100 mg/day) and clopidogrel (75 mg/day) were continued for 3 months followed by a life-long antiplatelet monotherapy with either aspirin or clopidogrel.

Center D: Immediately before stent placement, patients received an IV bolus of aspirin (500 mg) and an IV bolus of heparin (5000 IU). Alternatively, tirofiban was used. At the end of the intervention, a flat panel CT scan was performed to rule out intracranial hemorrhage; if so, the patients received a loading dose of clopidogrel $(600 \mathrm{mg})$ orally. Aspirin (100 mg/day) and clopidogrel (75 mg/day) were continued for 3 months and then switched to a life-long aspirin (100 mg/day) monotherapy.

\section{Exclusion Criteria}

Any infarction of equal to or more than one-third of the MCA territory or evidence of an intracranial hemorrhage on the initial CT scan led to exclusion. Additionally, all patients without persistent intracranial occlusion after extracranial stent placement were excluded.

\section{Endovascular Procedures}

The endovascular procedures have been described in detail previously. ${ }^{4,5,7,15}$ None of the centers used a balloon-guide occlusion catheter. In brief, the procedures were the following:

Antegrade approach: A large guide catheter (Neuron MAX 088; Penumbra, Alameda, California; Mach1; Boston Scientific, Natick, Massachusetts; VISTA BRITE TIP; Cordis, Fremont, California) was placed into the distal common carotid artery. A 0.014 -inch wire was then carefully navigated through the ICA occlusion up to the petrous portion in conjunction with a microcatheter. A slow and careful contrast injection was then performed to verify passage into the true lumen. Pre-stenting balloon angioplasty was performed whenever necessary with a 3.0- or 3.5-mm monorail balloon. The subsequent MT in the intracranial portions was performed in a usual manner. In case of a biaxial approach with a stent retriever (Trevo variants, Stryker, Kalamazoo, Michigan; Separator 3D, Penumbra; Solitaire AB/FR; Covidien, Irvine, California), the stent was passed with the guiding catheter before retraction of the stent retriever; in a triaxial set- 


\begin{tabular}{|c|c|c|c|c|c|}
\hline & All $(n=170)$ & Center A $(n=57)$ & Center B $(n=42)$ & Center C $(n=44)$ & Center $\mathrm{D}(n=27)$ \\
\hline Treatment period/characteristics & & $\begin{array}{l}\text { October } 2009 \text { to } \\
\text { July } 2014\end{array}$ & $\begin{array}{l}\text { March } 2007 \text { to } \\
\text { July } 2014\end{array}$ & $\begin{array}{l}\text { January } 2011 \text { to } \\
\text { February } 2014\end{array}$ & $\begin{array}{l}\text { December } 2009 \text { to } \\
\text { February } 2013\end{array}$ \\
\hline Age (yr) (median) (range) & $64(25-88)$ & $64(40-86)$ & $60(25-88)$ & $64(37-87)$ & $70(48-82)$ \\
\hline Male sex $(n / N)(\%)$ & $119 / 170$ (70\%) & $39 / 57(68 \%)$ & $30 / 42(71 \%)$ & $32 / 44(76 \%)$ & $18 / 27(67 \%)$ \\
\hline IV thrombolysis $(n / N)(\%)$ & $122 / 170(72 \%)$ & $49 / 57(85 \%)$ & $31 / 42(74 \%)$ & $19 / 44(43 \%)$ & $23 / 27(85 \%)$ \\
\hline Baseline NIHSS (median) (range) & $15(12-19)$ & $16(13-19)$ & $16(9-21)$ & $16(14-20)$ & $15(10-17)$ \\
\hline $\begin{array}{l}\text { Symptom onset to admission (min) } \\
\text { (median) (range) }\end{array}$ & $98(52-160)$ & $102(49-153)$ & $83(50-180)$ & $108(60-183)$ & $86(63-183)$ \\
\hline \multicolumn{6}{|l|}{ Distal occlusion site } \\
\hline Carotid-T $(n / N)(\%)$ & $51 / 170(30 \%)$ & $28 / 57(49 \%)$ & $17 / 42(40 \%)$ & $3 / 44(7 \%)$ & $3 / 27(11 \%)$ \\
\hline Terminal ICA $(n / N)(\%)$ & $3 / 170(2 \%)$ & $2 / 57(4 \%)$ & $1 / 42(2 \%)$ & - & - \\
\hline $\operatorname{MCA} M 1(n / N)(\%)$ & $99 / 170(58 \%)$ & $19 / 57(33 \%)$ & $19 / 42(45 \%)$ & $37 / 84(\%)$ & $24 / 27(89 \%)$ \\
\hline MCA M2 $(n / N)(\%)$ & $17 / 170(10 \%)$ & $8 / 57(14 \%)$ & $5 / 42(12 \%)$ & $4 / 44(9 \%)$ & - \\
\hline
\end{tabular}

Note:- - indicates none.

ting, the stent was passed with the intermediate catheter and the stent retriever was retracted into it to not interfere with the stent. No such precautions were necessary in cases of direct-aspirationtreatment technique without the use of a retriever.

Retrograde approach: Analogously, a large guide catheter was placed in the distal common carotid artery; the proximal ICA stenosis was then passed with a 0.014 -inch micro-guidewire followed by an intermediate catheter (054 or 5MAX, Penumbra; DAC, Stryker; Navien, Covidien). The intermediate catheter was positioned as close to the clot as possible, allowing lesional aspiration. We then performed MT using a stent retriever in the usual fashion. After successful revascularization of the occluded intracranial vessel, an exchange microwire was introduced over the intermediate catheter and then exchanged for the stent at the proximal occlusion/stenosis site.

\section{Imaging Evaluation}

All imaging data were analyzed at the level of the participating centers by an interventional neuroradiologist; the angiographic results were locally graded according to the TICI score. A successful recanalization was defined as a TICI result of $\geq 2 b$.

All postinterventional control CT scans of the patients were screened for intracranial hemorrhages, and all centers reported all parenchymal type 1 (parenchymal hematoma $[\mathrm{PH}] 1$ : bleeding $<30 \%$ of the infarcted area with a mild space-occupying effect and parenchymal hematoma) and type 2 ( $\mathrm{PH} 2$ : bleeding of $>30 \%$ of the infarcted area with a relevant space-occupying effect) hematomas and all sICHs, according to the European Cooperative Acute Stroke Study criteria (any apparently extravascular blood in the brain or within the cranium that was associated with clinical deterioration, as defined by an increase of $\geq 4$ points in the NIHSS score, or that led to death and that was identified as the predominant cause of the neurologic deterioration). ${ }^{17}$

\section{Clinical Evaluation}

A stroke neurologist assessed all patients clinically on admission (NIHSS) and discharge (NIHSS and mRS) from the stroke center and the rehabilitation unit (follow-up mRS at $\sim 90$ days; range, 70-100 days). In cases with missing follow-up data, the discharge mRS was used instead. ${ }^{18}$

\section{Data Analysis and Statistics}

The data were collected at each center according the above-mentioned criteria, pooled, and then analyzed at 1 of the 4 centers.
Continuous study parameters were compared among patients by either the Welch $t$ test in case of a normal distribution or by the Mann-Whitney $U$ test in case of a non normal distribution. The Fisher exact test was used for categoric variables. All statistical analyses were performed by using GraphPad Prism software, Version 6.1 (GraphPad Software, San Diego, California); the significance level was set at $\alpha=.05$.

\section{RESULTS}

One hundred seventy patients were treated between July 2007 and July 2014. The median age was 64 years (range, 25-88 years); $119 / 170(70 \%)$ were male. The patients presented after a median of 98 minutes (range, 52-160 minutes) with a median NIHSS score of 15 (range, 12-19). Distal occlusion sites were the following: MCA M1 in 99/170 (58\%), MCA M2 in 17/170 (10\%), terminal ICA in $3 / 170(2 \%)$, and carotid-T in $51 / 170(31 \%)$. IV thrombolysis was applied in 122/170 (72\%) patients (Table 1).

\section{Technical and Angiographic Results}

All patients received ICA stent placement with at least 1 stent, in most cases $(153 / 170,90 \%)$ with the Carotid Wallstent (Boston Scientific). One hundred thirty-three of 170 patients (78\%) underwent treatment with new-generation devices (stent retriever and/or direct aspiration catheter); the remainder were treated by aspiration with a first-generation aspiration catheter (Penumbra System, Penumbra). One hundred fifty-one of 170 cases (89\%) were performed with an antegrade approach. The median groin puncture to recanalization time was 88 minutes (range, 59-121 minutes); overall, the median symptom onset to recanalization time was 296 minutes (range, 236-367 minutes). A favorable angiographic result (TICI $\geq 2 \mathrm{~b}$ ) was achieved in $130 / 170$ cases (77\%); in another 21/170 (12\%), a TICI2a result could be reached. In the subgroup that underwent treatment with a modern stent retriever or direct aspiration, a favorable angiographic result was reached in 113/133 (85\%). The control CT scans revealed a $\mathrm{PH} 1$ in $13 / 170$ (8\%) and a $\mathrm{PH} 2$ in 11/170 patients (9\%). Of these 24 hematomas, only 15 were classified as $\mathrm{sICH}$, whereby $11 / 15(73 \%)$ led to death in the acute phase. The overall all-cause in-hospital mortality was 19\% (32/170). The median NIHSS score at discharge was 6 , and at the time of the follow-up examination, $62 / 170$ patients (36\%) had a favorable outcome (Table 2).

To identify factors contributing to the risk of sICH, we analyzed several cofactors in respect to the subgroups of patients with 


\begin{tabular}{|c|c|c|c|c|c|}
\hline & All $(n=170)$ & Center A $(n=57)$ & Center B $(n=42)$ & Center C $(n=44)$ & Center $\mathrm{D}(n=27)$ \\
\hline \multicolumn{6}{|l|}{ Clinical outcome } \\
\hline NIHSS at discharge (median) (range) & $6(3-12)$ & $6(3-11)$ & $8(4-15)$ & $8(3-15)$ & $5(2-10)$ \\
\hline $\mathrm{FU} m \mathrm{mRS} \leq 2$ & $62 / 170(36 \%)$ & $22 / 57(39 \%)$ & $16 / 42(38 \%)$ & $15 / 44(34 \%)$ & $9 / 27(33 \%)$ \\
\hline In-hospital mortality (all cause) & $32 / 170(19 \%)$ & $11 / 57(19 \%)$ & $5 / 42(12 \%)$ & $9 / 44(20 \%)$ & $7 / 27(26 \%)$ \\
\hline $\mathrm{PH}(n / N)(\%)$ & $13 / 170(8 \%)$ & $4 / 57(7 \%)$ & $2 / 42(5 \%)$ & $5 / 44(11 \%)$ & $2 / 27(7 \%)$ \\
\hline $\mathrm{PH} 2(n / N)(\%)$ & $11 / 170(6 \%)$ & $5 / 57(7 \%)$ & $2 / 42(5 \%)$ & $1 / 44(2 \%)$ & $3 / 27(11 \%)$ \\
\hline $\operatorname{sICH}(n / N)(\%)$ & $15 / 170(9 \%)$ & $5 / 57(9 \%)$ & $3 / 42(7 \%)$ & $3 / 44(7 \%)$ & $4 / 27(15 \%)$ \\
\hline \multicolumn{6}{|l|}{ Angiographic outcome } \\
\hline $\begin{array}{l}\text { Groin puncture to recanalization } \\
\text { (min) (median) (range) }\end{array}$ & $88(59-121)$ & $75(56-95)$ & $81(41-118)$ & 111 (70-148) & 119 (84-147) \\
\hline $\begin{array}{l}\text { Symptom onset to recanalization } \\
\text { (min) (median) (range) }\end{array}$ & $296(236-367)$ & $263(217-317)$ & $332(259-401)$ & $317(252-420)$ & $306(227-365)$ \\
\hline $\mathrm{TICl} \geq 2 \mathrm{~b}(n / N)(\%)$ & $130 / 170(77 \%), 113 / 133(85 \%)^{\mathrm{b}}$ & $48 / 57(84 \%)$ & $22 / 42(53 \%)^{a}$ & $36 / 44(82 \%)$ & $24 / 27(89 \%)$ \\
\hline $\operatorname{TICl} 2 \mathrm{a}(n / N)(\%)$ & $21 / 170(12 \%)$ & $3 / 57(5 \%)$ & $13 / 42(31 \%)$ & $4 / 44(9 \%)$ & $1 / 27(4 \%)$ \\
\hline
\end{tabular}

Note:-FU indicates follow-up.

a Includes results from 2007/2008, treatment without a stent retriever.

b Only cases with stent retriever or direct aspiration treatment.

Table 3: Potential risk factors for sICH after stenting and MT

\begin{tabular}{|c|c|c|c|}
\hline & sICH & No sICH & $P$ Value \\
\hline \multicolumn{4}{|l|}{ Characteristics } \\
\hline Age (yr) (median) (range) & $71(46-86)$ & $64(25-88)$ & .1 \\
\hline Age above median $(n / N)(\%)$ & $10 / 15(66 \%)$ & $74 / 155(48 \%)$ & .2 \\
\hline Male sex $(n / N)(\%)$ & $12 / 15(80 \%)$ & $107 / 155(70 \%)$ & .6 \\
\hline IV thrombolysis $(n / N)(\%)$ & $8 / 15(53 \%)$ & $114 / 155(74 \%)$ & .1 \\
\hline Initial ASPECTS (median) (IQR) & $7(6-9)$ & $7(5-8)$ & 1.0 \\
\hline Symptom onset to recanalization (min) (median) (range) & $300(264-419)$ & $294(233-363)$ & .3 \\
\hline Groin puncture to recanalization (min) (median) (range) & $95(68-140)$ & $83(58-120)$ & .2 \\
\hline $\mathrm{TICl} \geq 2 \mathrm{~b}(n / N)(\%)$ & $13 / 15(87 \%)$ & $117 / 155(75 \%)$ & .5 \\
\hline \multicolumn{4}{|l|}{ Occlusion site } \\
\hline Carotid-T $(n / N)(\%)$ & $4 / 15(27 \%)$ & $47 / 155(30 \%)$ & 1.0 \\
\hline $\operatorname{MCA}(n / N)(\%)$ & $11 / 15(73 \%)$ & $88 / 155(57 \%)$ & .3 \\
\hline \multicolumn{4}{|l|}{ Antiplatelet medication $(n / N)(\%)$} \\
\hline Eptifibatide, tirofiban & $5 / 57(9 \%), 7 / 71(11 \%)$ & 52/57 (91\%), 64/71 (89\%) & 1.0 \\
\hline Eptifibatide, aspirin + clopidogrel & $5 / 57(9 \%), 3 / 42(7 \%)$ & $52 / 57(91 \%), 39 / 42(93 \%)$ & 1.0 \\
\hline Tirofiban, aspirin + clopidogrel & $7 / 71(11), 3 / 42(7 \%)$ & $66 / 71(89 \%), 39 / 42(93 \%)$ & .7 \\
\hline
\end{tabular}

Note:-MT indicates mechanical thrombectomy; IQR, interquartile range.

and without sICH (Table 3). We could not find statistically significant differences among the median age (71 versus 64 years, $P=.1$ ), the percentage of male patients ( $80 \%$ versus $70 \%, P=.6$ ), the number of patients who received iv thrombolysis (53\% versus $74 \%$ ), the initial ASPECTS ( 7 versus 7, $P=1.0$ ), the median time from symptom onset to recanalization (300 versus 294 minutes, $P=.3$ ), the groin puncture to recanalization timings ( 95 versus 83 minutes), the rate of favorable angiographic results ( $87 \%$ versus $75 \%$ ), or the occlusion sites. Additionally, there was no significant difference between the rates of sICH in respect to the administered antiplatelet medication (eptifibatide versus tirofiban, $P=$ 1.0; tirofiban versus aspirin and clopidogrel, $P=.7$; eptifibatide versus aspirin and clopidogrel, $P=1.0$ ).

\section{DISCUSSION}

Endovascular therapies for acute ischemic stroke caused by underlying large-artery occlusion have emerged significantly with time, and very recently randomized trials have shown a significant benefit regarding the rate of functional independence after endovascular treatment. ${ }^{13,14,19}$ However, $10 \%-20 \%$ of these patients with acute ischemic stroke present with an additional proximal high-grade stenosis or occlusion of the ipsilateral ICA. ${ }^{1}$ These patients have been excluded from several studies investigating the efficacy of mechanical thrombectomy, though it has been shown that IV thrombolysis alone is less effective in these cases. ${ }^{3,11}$ Endovascular therapy consisting of ICA stent placement and anterior circulation thrombectomy has yielded promising results in small case series so far. ${ }^{4,8}$ Alas, bleeding complications, especially in the setting of a mandatory dual antiplatelet medicationsometimes even in addition to IV thrombolysis—might impose a higher risk for added morbidity and mortality in the postinterventional phase.

The endovascular treatment of acute tandem occlusions using ICA stent placement has been investigated for more than a decade. ${ }^{20,21}$ At the same time, there was a fundamental development of catheters and clot-extraction devices; stent retrievers have been shown to be technically and clinically superior to older devices. ${ }^{11,12}$ Recently, several case series investigated the efficacy and safety of endovascular therapy when ICA stent placement was performed in combination with anterior circulation thrombectomy (On-line Table). Most interesting, these series report relevant differences of the revascularization efficacy, with TICI $\geq 2 b$ results ranging from $63 \%$ to $79 \%$ of cases and the rate of favorable clinical outcome spanning a range of $29 \%-76 \% .^{5-10,22}$ Moreover, the reported rates of sICH range from $0 \%$ to almost $22 \%$, most probably due to low numbers of included patients in single-center designs (On-line Table).

AJNR Am J Neuroradiol 36:2340-45 Dec 2015 www.ajnr.org 
The present retrospective, multicenter trial represents a large number of patients with acute ischemic stroke with underlying extracranial ICA stenosis/occlusion and an additional anterior circulation occlusion treated by ICA stent placement and anterior circulation MT. Compared with data published by Malik et al, ${ }^{9}$ (77 patients with such tandem occlusions) who did not use stent retrievers for the intracranial recanalization, our rates of favorable angiographic results (75\% [Malik et al] versus $77 \%$ ), clinical outcome (42\% versus $36 \%$ ), and sICH ( $10 \%$ versus $9 \%)$ are in the same range. When comparing our data with a recently published meta-analysis, we found the rate of sICH and favorable clinical outcome to be similar $(9 \%$ sICH in our cohort versus $7 \%$ in the group that was treated by stent retrievers and ICA stent placement and 36\% versus 35\% favorable outcome). ${ }^{23}$

In contrast to more recent publications, we found the rate of sICH to be lower in our series compared with data that were published by Heck and Brown ${ }^{6}\left(21 \%\right.$ sICH) or Stampfl et $\mathrm{al}^{8}$ $(17 \%$ sICH $)$, though they used similar antiplatelet medication strategies. ${ }^{6,8}$ Notably, the very high rate of sICH in the Heck and Brown cohort was associated with the use of abciximab (4/13 [31\%] sICH in the group of patients who received abciximab) and a high mean age of their patients.

Regarding the clinical outcome, our results (36\% favorable outcome) lay between the results of the above-mentioned studies (52\% and 29\% respectively).

Antiplatelet medication is a prerequisite for ICA stent placement to prevent in-stent thrombosis, and it might go along with a higher risk of sICH, especially if IV thrombolysis is administered additionally. Our retrospective multicenter study could not find significant differences between the various antithrombotic approaches that were used in the participating centers (Table 3 ). The administration of neither tirofiban nor eptifibatide seems to be associated with an increased risk of sICH. Most interesting, we could not determine any specific cofactor that increased the risk of intracranial hemorrhage peri-interventionally because the variables of age, sex, procedural timings, revascularization results, initial ASPECTS, and rate of IV thrombolysis were not significantly different among the groups (Table 3 ).

Most important, our study did not show significant differences regarding the rate of sICH compared with recently published, randomized trials like the Randomized Trial of IntraArterial Treatment for Acute Ischemic Stroke, which reported an $\mathrm{sICH}$ rate of $8 \%(P=.7)$ in the endovascular arm or the Intra-Arterial Versus Systemic Thrombolysis for Acute Ischemic Stroke expansion trial, which also found the sICH rate to be $6 \%$ in both arms $(P=.3) \cdot{ }^{13,24}$

Several limitations have to be considered when interpreting the current data, most important the retrospective study design, the missing control groups, and the lack of core lab control for imaging evaluation, which might have biased the angiographic results toward higher scores of successful recanalizations. The participating centers used different antiplatelet regimens, which might still have an influence on the rate of sICH but could not be elucidated in the present study because it might still be statistically underpowered to detect such an effect.

\section{CONCLUSIONS}

Emergency stent placement in the extracranial ICA combined with anterior circulation thrombectomy is safe and effective. The rate of good outcome is in the range of MT alone. The endovascular treatment of these complex cases is not associated with a significantly higher risk of postinterventional sICH compared with MT without concomitant extracranial stent placement.

Disclosures: Daniel Behme_UNRELATED: Travel/Accommodations/Meeting Expenses Unrelated to Activities Listed: Penumbra. Anastasios Mpotsaris - UNRELATED: Consultancy: Penumbra (minor honoraria); Travel/Accommodations/Meeting Expenses Unrelated to Activities Listed: Neuravi, Penumbra, Comments: travel grants. Christoph Johannes Maurer-UNRELATED: Grants/Grants Pending: Boston Scientific, Stryker, Comments: I received educational grants from Boston Scientific and Stryker; Travel/Accommodations/Meeting Expenses Unrelated to Activities Listed: MicroVention, Comments: I received a travel grant for the meeting of the German Society of Neuroradiology from MicroVention. Ansgar Berlis-UNRELATED: Consultancy: consultancy agreements with Covidien, Stryker, and MicroVention for proctoring; Payment for Lectures (including service on Speakers Bureaus): honorarium for invited lectures from Penumbra and Stryker. Michael Knauth—UNRELATED: Payment for Lectures (including service on Speakers Bureaus): Siemens (paid lecture on intracranial thrombectomy). Thomas Liebig-UNRELATED: Consultancy: consulting and proctoring for MicroVention; Acandis; Sequent Medical, Germany. Werner Weber-UNRELATED: Payment for Lectures (including service on Speakers Bureaus): Penumbra, Comments: Most of the patients from our group were treated with devices from Penumbra.

\section{REFERENCES}

1. Grau AJ, Weimar C, Buggle F, et al. Risk factors, outcome, and treatment in subtypes of ischemic stroke: the German stroke data bank. Stroke 2001;32:2559-66 CrossRef Medline

2. Rubiera M, Ribo M, Delgado-Mederos R, et al. Tandem internal carotid artery/middle cerebral artery occlusion: an independent predictor of poor outcome after systemic thrombolysis. Stroke 2006;37:2301-05 CrossRef Medline

3. Kim YS, Garami Z, Mikulik R, et al; CLOTBUST Collaborators. Early recanalization rates and clinical outcomes in patients with tandem internal carotid artery/middle cerebral artery occlusion and isolated middle cerebral artery occlusion. Stroke 2005;36:869-71 CrossRef Medline

4. Mpotsaris A, Bussmeyer M, Buchner H, et al. Clinical outcome of neurointerventional emergency treatment of extra- or intracranial tandem occlusions in acute major stroke: antegrade approach with Wallstent and Solitaire stent retriever. Clin Neuroradiol 2013;23: 207-15 CrossRef Medline

5. Lockau H, Liebig T, Henning T, et al. Mechanical thrombectomy in tandem occlusion: procedural considerations and clinical results. Neuroradiology 2015;57:589-98 CrossRef Medline

6. Heck DV, Brown MD. Carotid stenting and intracranial thrombectomy for treatment of acute stroke due to tandem occlusions with aggressive antiplatelet therapy may be associated with a high incidence of intracranial hemorrhage. J Neurointerv Surg 2015;7:170-75 CrossRef Medline

7. Maurer CJ, Joachimski F, Berlis A. Two in one: endovascular treatment of acute tandem occlusions in the anterior circulation. Clin Neuroradiol 2014 Jul 3. [Epub ahead of print] Medline

8. Stampfl S, Ringleb PA, Möhlenbruch M, et al. Emergency cervical internal carotid artery stenting in combination with intracranial thrombectomy in acute stroke. AJNR Am J Neuroradiol 2014;35: 741-46 CrossRef Medline

9. Malik AM, Vora NA, Lin R, et al. Endovascular treatment of tandem extracranial/intracranial anterior circulation occlusions: preliminary single-center experience. Stroke 2011;42:1653-57 CrossRef Medline

10. Cohen JE, Gomori JM, Rajz G, et al. Extracranial carotid artery stenting followed by intracranial stent-based thrombectomy for acute tandem occlusive disease. J Neurointerv Surg 2015;7:412-17 CrossRef Medline 
11. Saver JL, Jahan R, Levy EI, et al. Solitaire flow restoration device versus the Merci retriever in patients with acute ischaemic stroke (SWIFT): a randomised, parallel-group, non-inferiority trial. Lancet 2012;380:1241-49 CrossRef Medline

12. Nogueira RG, Lutsep HL, Gupta R, et al; TREVO 2 Trialists. Trevo versus Merci retrievers for thrombectomy revascularisation of large vessel occlusions in acute ischaemic stroke (TREVO 2): a randomised trial. Lancet 2012;380:1231-40 CrossRef Medline

13. Berkhemer OA, Fransen PS, Beumer D, et al. A randomized trial of intraarterial treatment for acute ischemic stroke. NEngl J Med 2015; 372:11-20 CrossRef Medline

14. Goyal M, Demchuk AM, Menon BK, et al; ESCAPE Trial Investigators. Randomized assessment of rapid endovascular treatment of ischemic stroke. New Engl J Med 2015;372:1019-30 CrossRef Medline

15. Behme D, Kowoll A, Mpotsaris A, et al. Multicenter clinical experience in over 125 patients with the Penumbra Separator 3D for mechanical thrombectomy in acute ischemic stroke. J Neurointerv Surg 2014 Nov 3. [Epub ahead of print] CrossRef Medline

16. Psychogios MN, Kreusch A, Wasser K, et al. Recanalization of large intracranial vessels using the Penumbra system: a single-center experience. AJNR Am J Neuroradiol 2012;33:1488-93 CrossRef Medline

17. Hacke W, Kaste M, Bluhmki E, et al; ECASS Investigators. Throm- bolysis with alteplase 3 to 4.5 hours after acute ischemic stroke. N Engl J Med 2008;359:1317-29 CrossRef Medline

18. Ovbiagele B, Saver JL. Day-90 acute ischemic stroke outcomes can be derived from early functional activity level. Cerebrovasc Dis 2010; 29:50-56 CrossRef Medline

19. Campbell BC, Mitchell PJ, Kleinig TJ, et al; EXTEND-IA Investigators. Endovascular therapy for ischemic stroke with perfusion-imaging selection. N Engl J Med 2015;372:1009-18 CrossRef Medline

20. Nedeltchev K, Brekenfeld C, Remonda L, et al. Internal carotid artery stent implantation in 25 patients with acute stroke: preliminary results. Radiology 2005;237:1029-37 CrossRef Medline

21. Fischer U, Mono ML, Schroth G, et al. Endovascular therapy in 201 patients with acute symptomatic occlusion of the internal carotid artery. Eur J Neurol 2013;20:1017-24, e87

22. Puri AS, Kühn AL, Kwon HJ, et al. Endovascular treatment of tandem vascular occlusions in acute ischemic stroke. J Neurointerv Surg 2015;7:158-63 CrossRef Medline

23. Kappelhof M, Marquering HA, Berkhemer OA, et al. Intra-arterial treatment of patients with acute ischemic stroke and internal carotid artery occlusion: a literature review. J Neurointerv Surg 2015; 7:8-15 CrossRef Medline

24. Ciccone A, Valvassori L. Endovascular treatment for acute ischemic stroke. N Engl J Med 2013;368:2433-34Medline 